\title{
SCHISTOSOMA MANSONI: IMPLANTE DE VERMES NA CAVIDADE PERITONEAL VISANDO IMUNOPROTEÇÃO (1)
}

\author{
Paulo Marcos Z. COELho (2), Silvia E. GERKEN (2) \& Carios aberto P. TAvares (3)
}

\section{R E S U M O}

Tentou-se obter imunoproteção contra infecção cercariana pela inoculação de vermes vivos na cavidade peritoneal de camundongos. Embora os vermes sobrevivessem bem nestas condições e não ocorresse postura de ovos, năo foi possivel obter imunoproteção. Também a inoculação de ovos viáveis por via sanguínea e peritoneal não propiciou o aparecimento de imunoproteção nos camundongos com vermes na cavidade peritoneal.

UNIMERIMOS: Schistosoma mansoni; Implante de vermes; Cavidade peritoneal; Imunoproteção.

\section{N T R O D U G $\tilde{A} O$}

Um sistema de vacinação aplicável tem por princípio básico a obtenção de imunida. de protetora, contra os agentes infecciosos, causando um mínimo de lesões ao hospedeiro.

$\mathrm{Na}$ esquistossomose mansônica, só se consegue de maneira consistente obter imunida. de protetora por dois processos: imunidade concomitante e por infecção com cercárias ou esquistossômulos irradiados ${ }^{5}$. A imunidade concomitante já foi verificada em diversos hospedeiros, a saber: camondongos $5,6,8,9,11,12$, 16,21 , macacos rhesus 31 , ratos $10,25,30$ e hamsters 20,21 . Por outro lado, conforme revisão de DEAN 5 , inúmeros trabalhos mostram o efeito protetor de formas jovens irradiadas do S. mansoni, cercárias e esquistossômulos. Ambos os processos citados utilizam formas vivas do parasita na infecção primária. $O$ desenvolvimento da imunidade concomitante depende da presença de vermes adultos vivos no sistema porta para, continuamente, estimularem a resposta imunoprotetora. Nesse ca- so, verifica se também o quadro normal da doença com as evidentes implicações patológicas. No processo de vacinação por cercárias ou esquistossômulos irradiados, ainda que a irrađiação provoque a morte rápida dos organismos utilizados no processo de vacinação, muitas dúvidas ainda permanecem quanto à reprodutibilidade dos resultados. Uma série de variáveis tais como: dose ideal em Krad, variação da imunoproteção frente a diferentes cepas do S. mansoni, linhagens de camundongos, vias de inoculação, tempo ideal para se produzir a imunidade protetora, tempo de duração desta imunidade, pode interferir na reprodutibilidade dos resultados $2,5,7,14,15,17,18$, 19,26,27,28,29. it importante frizar que ambos os processos (imunidade concomitante ou irradiação) induzem somente a uma imunidade parcial, isto é, sempre algumas cercárias da infecção desafio conseguem atingir o estádio do verme adulto, produzindo desta maneira uma infecção ativa.

(1) Trabalho executado com auxílio financeiro do CNPq e FINETP, Brasil.

(2) Departamento de Parasitologia e Grupo Interdepartamental de Estudos sobre Esquistossomose (GIDE), ICB/UFMG.

(3) Departamento de Bioquímica-Imunologia, ICB/UFMG.

Endereço para correspondência: Prof. Paulo Marcos Z. Coelho, GDE-ICB/UFMG. Caixa Postal 2486. CEP 30161 Belo Horizonte, MG., Brasil. 
COELHO, P. M. Z.; GERKEEN, S. E. \& TAVARES, C. A. P. - Schistosoma mansoni: implante de vermes na cavidado peritoneal visando imunoproteção. Rev. Inst. Med. trop. São Paulo, 29:361-366, 1987.

f́ conhecido que o ovo é o elemento fundamental na patologia da esquistossomose ${ }^{22}$ e também que os vermes de 20 dias, introduzidos na cavidade peritoneal, não migram pa ra o sistema porta sanguíneo, não põem ovos e podem sobreviver por vários meses nestas condiçōes ${ }^{4,23}$. Logo, tornou-se consistente a hipótese de se tentar obter um tipo de imunidade concomitante pela presença de vermes na cavidade peritoneal sem a patologia clássica da doença. Também foram feitas associações com vermes na cavidade peritoneal e inóculo de ovos na veia caudal e cavidade peritoneal visando esclarecer uma possivel sinergia imunoprotetora do ovo com os vermes implantados na cavidade peritoneal.

\section{MATERIAL E METODOS}

\section{Camundongos}

Foram usados camundongos de linhagens isogênicas CBA e C57 BL-10 e não isogênica, Swiss.

\section{Cepa do. Schistosoma mansoni}

Foi utilizada a cepa LE (BH) do S. mansoni. Esta cepa é mantida nos laboratórios do GIDE (Grupo Interdepartamental de Estudos sobre Esquitossomose) hâ mais de 20 anos, por passagem em hamster e Biomphalaria glabrata.

Obtenção de vermes de 20 dias e inoculação na cavidade peritoneal de camundongos receptores

Foram inoculadas 500 cercárias, via subcutânea, em camundongos albinos. Vịnte dîas após, os camundongos foram sacrificados e perfundidos com a solução balanceada de Hanks (técnica de PELLEGRINO \& SIQUEIRA ${ }^{22}$ com pequenas modificações). Os vermes obtidos foram então lavados por sedimentação, por 3 vezes, em solução de Hanks. Foram contados em microscópio estereoscópico e um inóculo de cerca de 50 vermes por $\mathrm{ml}$ foi injetado na cavidade peritoneal dos camundongos receptores.

Obtenção de ovos viáveịs de $S$. mansoni
Os ovos foram obtidos de fígado de hamsters previamente infectados com 200 cercárias de S. mansoni, segundo técnica de JAMES \& COLLEY ${ }^{13}$.

Experimento I - Camundongos com vermes na cavidade peritoneal e imunoproteção con. tra desafio por cercárias

Aos 90 dias após o inóculo dos vermes na cavidade peritoneal, os camundongos "vacinados" e seus respectivos controles foram submetidos à infecção transcutânea por 100 cercárias (técnica de BARBOSA et al.1). Vinte dias pós o desafio, os camundongos foram sacrificados e submetidos à técnica de PEREI$\mathrm{RA}$ et al. ${ }^{24}$, para recuperação de vermes na cavidade peritoneal, e usou-se a técnica des. crita por PELLEGRINO \& SIQUEIRA 22, modificada, para recuperação de vermes do sistema porta. Os vermes foram contados separadamente. $O$ grau de desenvolvimento dos vermes em função da idade (110 dias dos vermes na cavidade peritoneal e 20 dias da infecção desafio, obtidos do sistema porta) permitiu distinguir facilmente as duas populações.

Experimento II - Vermes na cavidade perito. neal de camundongos mais ovos viáves inoculados via sangüínea e via peritoneal visando imunoproteça

Nos grupos com vermes na cavidade peritoneal e respectivos controles, foram inoculados 1.800 ovos viáveis, por duas vezes, nos $600^{\circ}$ e $70^{\circ}$ dias após implantação dos vermes, via veia caudal e via cavidade peritoneal. Quinze đias após o último inóculo, os grupos foram desafiados com 100 cercárias, por via transcutânea (técniç de BARBOSA et al.1). Vinte dias após a exposição cercariana, os camundongos foram sacrifieados para recuperação de vermes da cavidade peritoneal e do sistema porta. Os vermes das duas localizaçóes foram contados separadamente, como descrito no Experimento I.

\section{Análise estatistica}

A análise estatística foi realizada utilizando-se o teste $\mathrm{t}$ de Student, análise de variância e o teste de Scheffé ${ }^{32}$. 
COELHO, P. M. Z.; GERKEM, S. E. \& TAVARES, C. A. P. - Schistosoma mansoni: implante de vermes na càvidade peritoneal visando imunoproteçäo. Rev. Inst. Med. trop. São Paulo, 29:361-366, 1987.

\section{RESULTADOS}

A Tabela I mostra a recuperação dos vermes do sistema porta de camundongos de diferentes linhagens que tinham ou não vermes implantados na cavidade peritoneal (Experimento I).

T A B E I A I

Recuperação de vermes do sistema porta de camundongos de diferentes linhagens que receberam implantes de vermé na cavidade peritorieal (CP)

\begin{tabular}{|c|c|c|c|c|c|}
\hline \multirow{2}{*}{$\begin{array}{l}\text { Experi- } \\
\text { mento }\end{array}$} & \multirow{2}{*}{$\begin{array}{l}\text { Linhagem } \\
\text { dos } \\
\text { camundongos }\end{array}$} & \multirow{2}{*}{$\begin{array}{l}\text { Dia } \\
\text { aposs } \\
(100\end{array}$} & \multirow{2}{*}{$\begin{array}{l}\text { da infeccäo desafio } \\
\text { implante dos vermes } \\
\text { na C.P. } \\
\text { cercárias, via trans- } \\
\text { cutanea) }\end{array}$} & \multicolumn{2}{|c|}{$\begin{array}{c}\text { Recuperacão dos vermes do Sistema Porta (21 dias } \\
\text { após infecç̄o com cercárias) }\end{array}$} \\
\hline & & & & $\begin{array}{l}\text { Normais } \\
\text { (n) }\end{array}$ & $\begin{array}{l}\text { Com vermes na } \\
\text { cavidade peritoneal } \\
\text { (n) }\end{array}$ \\
\hline 1 & Swiss & & $1200^{\circ}$ & $31,4 \underset{(11)}{ \pm} 11,0$ & $30,2 \underset{(11)}{ \pm} 7,7$ \\
\hline 2 & Swiss & & $1000^{\circ}$ & $\underset{(14)}{13,9} \pm 9,5$ & 16,0. $\underset{(12)}{8,2}$ \\
\hline 3 & Swiss & & $1350^{\circ}$ & $\begin{array}{l}20,8 \pm 11,2 \\
\text { (8) }\end{array}$ & $16,3 \pm 7,3$ \\
\hline 4 & CBA & & $750^{\circ}$ & $\begin{array}{l}32,9 \pm 8,7 \\
(11)\end{array}$ & $25,4 \pm 14,1$ \\
\hline 5 & CBA & & $1000^{\circ}$ & $\begin{array}{l}40,8 \pm 10,0 \\
(6)\end{array}$ & $\begin{array}{l}47,1 \pm \underset{(10)}{ } 20,4 \\
\text { (10) }\end{array}$ \\
\hline 6 & C57 PL/10 & & $75 .^{\circ}$ & $30,2 \pm 12,5$ & $\begin{array}{l}30,3 \pm 14,0 \\
(8)\end{array}$ \\
\hline
\end{tabular}

Média e desvio padråo da recuperaçáo de vermes da cavidade peritoneal:

Experimento $1=13,9 \pm 11,8 ; 2=5,5 \pm 1,1 ; 3=20,0 \pm 16,1 ;$ $4=14,4 \pm 5,9 ; 5=18,2 \pm 4,7 ; 6=11,4 \pm 6,9$.

(n) = número de animais em cada grupo

A análise estatística, pelo teste $t$ de Student, não detectou nenhuma diferença estatisticamente significativa entre as médias de recuperação de vermes do sistema porta dos camundongos "vacinados" e as médias de seus respectivos controles.
A. Tabela II mostra os resultados da tentativa de se obter imunoproteção contra infecção desafio com cercárias pela presença simultânea de vermes na cavidade peritoneal e ovos inoculados na cavidade peritoneal ou na veia caudal (Experimento II).

\section{T A.B L A II}

Recuperação de vermes do sistema porta de camundongos (Swiss) que receberam implante de vermes na cavidade peritoneal e ovos viáveis inoculados por via sanguínea ou na cavidade peritóneal

\begin{tabular}{|c|c|c|c|c|c|c|}
\hline & \multicolumn{3}{|c|}{ Grupo I (Com vermes na cavidade peritoneal) } & \multicolumn{3}{|c|}{ Grupo II (Sem vermes na cavidade perttoneal) } \\
\hline & \begin{tabular}{l}
\multicolumn{1}{c}{ GI 1 } \\
Oros inoculados \\
na veia caudal
\end{tabular} & $\begin{array}{c}\text { GI 2 } \\
\text { Ovos inoculados } \\
\text { na cavidade } \\
\text { peritoneal }\end{array}$ & $\begin{array}{c}\text { GI } 3 \\
\text { Sem oros }\end{array}$ & $\begin{array}{l}\text { GII I } \\
\text { Ovos inocilados } \\
\text { na veia caudal }\end{array}$ & $\begin{array}{c}\text { GII 2 } \\
\text { Ovos inoculados } \\
\text { na cavidade } \\
\text { peritoneal }\end{array}$ & $\begin{array}{c}\text { GII } 3 \\
\text { Sem ovos }\end{array}$ \\
\hline $\begin{array}{l}\text { Média de vermes recu- } \\
\text { perados do sistema porta } \\
\text { e desvio padráo }\end{array}$ & $26,8 \pm 8,7$ & $16,3 \pm 4,0$ & $16,0 \pm 7,1$ & $21,3 \pm 5,7$ & $19,1 \pm 6,6$ & $16,8 \pm 7,0$ \\
\hline (n) $=$ & (9) & (8) & (10) & (11) & (10) & (4) \\
\hline
\end{tabular}

A análise de variancia e o teste de Scheffé não detectaram diferença estatísticamente signfficativa entre as médias de recuperação de vermes do sistema porta dos dois grupos estudados decorrente da infecçāo desafio). 
COELFO, P. M. Z.; GERKEN, S. E. \& TAVARES, C. A. P. - Schistosoma mansoni: implante de vermes na cavidede peritoneal visando imunoproteçäo. Rev. Inst. Med. trop. Sáo Paulo, 29:361-366, 1987.

\section{DISGUSSAO}

Os resultados das Tabelas I e II mostram que não foi possivel induzir um estado de imunoproteção em camundongos contra infecção cercariana pela presença de vermes vivos na cavidade peritoneal, isto não ocorrendo nem mesmo por injeção simultânea de ovos viáveis, seja por via sanguínea ou cavidade peritoneal.

Tais resultados, em parte, reforçam os achados de DEAN et al. ${ }^{6}$, que verificaram que o grau de imunidade na esqustossomose estaria diretamente relacionado com d grau de imunopatologia desenvolvida no animal. Estes resultados foram posteriormente corroborados por WILSON et al. ${ }^{33}$. Ainda neste sentido, a maioria dos experimentos conduzidos com vermes de um só sexo, portanto sem presença de ovos e, consequientemente, sem pato. logia apreciável, não resultaram na indução de imunoproteção ou, se resultaram, esta imunoproteção se manifestou de maneira pouco significativa $3,5,8$. De acordo com GERKEN 9, a imunidade por vermes unisexuados só se expressaria de maneira detectável após período superior a 33 semanas da primo infecção. Assim, na extensa revisão de DEAN ${ }^{5}$, verifica-se que alguns poucos autores conseguiram algum grau de proteção só com a presença de vermes unisexuados (machos ou fêmeas) e vermes irradiados inférteis." Por outro lado, alguns autores conseguiram imunoproteção inoculando somente ovos na veia caudal de camundongos normais ${ }^{5}$. Conforme estas últimas consideraçōes, vermes ou ovos poderiam, em determinadas circunstâncias, induzir a um estado de imunoproteção, embora estes resultados não sejam corroborados pela maioria dos autores que trabalharam nesta linha. Pelo exposto, pode-se inferir que os mecanismos que regem imunidade adquirida na esquistossomose murina são ainda sujeitos a muita polêmica e, na literatura, são comumente detectados resultados conflitantes. Provavelmente, inumeras variáveis tais como: linhagem dos camundongos, cepa do $\mathbf{S}$. man. soni, via do inóculo da primo infecção, processo e tempo de imunização, idade e sexo dos animais, influiram nos resultados obtidos pelos diversos autores.
Portanto, nossas conclusões; fundamentadas em nossos resultados, obtidos com a cepa LE do S. mansoni, com as linhagens de camundongos estudadas e com a abordagem metodológica utilizada, nos permitem afirmar que, vermes vivos implantados na cavidade peritoneal de camundongos, mesmo com inoculação simultânea de ovos viáveis pela via circulató. ria ou peritoneal, não induzem a um estado de imunoproteção contra infecções desafio por cercárias.

\section{SUMMARY}

Schistosoma mansoni: implantation of worms into the peritoneal cavity aiming at the induduction of immunoprotection

An attempt has been made to induce immunoprotection against cercarial infection through inoculation of live worms into the peritoneal cavity of mice. Although the worms were able to survive normally under these conditions, and no egg-laying could be detected, immunoprotection was obtained. Likewise, the inoculation of viable eggs, by circulatory and peritoneal routes, did not provide immunoprotection in mice with worms in the peritoneal cavity.

\section{REFERENCIAS BIBLIOGRAFICAS}

1. Barbosa, M. A.; PELILFGRINo, J.; COFLHO, P. M. Z. \& SAMPAIO, I. B. M. - Quantitative aspects of the migration and evolutive asynchronism of Schisto. soma mansoni in mice. Rev. Inst. Med. trop. S. paulo. 20: 121-132, 1978.

2. BICKLE, Q. D.; ANDREWS, B. J.; DOENHOFF, $M$. J.; FORD, M. J. \& TAYLOR, M. G. - Resistance against Sehistosoma mansoni induced by highly irradiated infections; studies on species specificity of immunization and attempts to transfer resistance. $\mathbf{P a}$ rasitology, 90: 301-312, 1985.

3. EICKIE; Q. D.; BAIN, J.; McGREGOR, A. \& DOENHOFF, M. - Factors affecting the acquisition of re sistance against Schistosoma mansoni in the mouse. III - The failure of primary infections with cerca riae of one sex to induce resistance to reinfection. Trans. roy. Soc. trop. Med. Hyg., 73: 37-41, 1979.

4. COELHO, P. M. Z.; PELLEGRINO, J.; PEREIRA, L. H. \& MELLO, R. T. - Migration of schistosiomula (Schistosoma mansoni) collected from hamster and inoculated intraperitoneally in mice. Trans. roy. Soc. trop. Med. Hyg., 70: 161, 1976.

5. DEAN, D. A. - A review of Schistosoms and relatec general: acquired resistance in mice. Exp. Parasit.. 55: 1-104, 1983. 
COELHO, P. M. Z; GERKEN, S. E. \& TAVARES; C. A. P. - Schistosoma mansoni: implante de vermes na cavidado peritoneal visando imunoproteção. Kev. Inst. Med. trop. São Paulo, 29:361-366, 1987.

6. DEAN, D. A.; BUKOWSKI, M. A. \& CHEEVHR, A W. - Relationship between acquired resistance, portal hypertension and lung granuloma in ten strains of mice infected with Schistosoma mansoni. Amer. J. trop. Med. Hyg., 30: 806-814, 1981a.

7. DEAN, D. A.; MANGOLD, B. L.; GEORGI, J. R. \& JACOBSON, R. H. - Comparison of Schistosoma mansoni migration patterns in normal and irradiated cer. caria-immunized mice by means of autoradiographic analysis; evidence that worm elimination occurs after the skin phase in immunized mice. Aaner. J. trop. Med. Hyg., 33: 86-96, 1984 .

8. DEAN, D. A.; MINARD, P.; STIRE'WALT, M. A.; VANNIER, W. E. \& MURREL, K. D. - Resistance of mice to secondary infection with Schistosoma man. soni. I. Comparison of bisexual and unisexual initial infections. Amer. J. trop. Med. Hyg., 27: 951-956, 1978 .

9. GERKEN, S. E. - Schistosoma mansoni: Resistência cutânea de camundongos normais e portadores de infecção primária. Belo Horizonte, 1986. (Tese de Doutoramento - Dept.o de Parasitologia, ICB/UFMMG).

10. GóES, A. M. - Estudos in vivo dos mecanismos de imunidade 'protetora dependente de anticorpos que atuam na morte de esquistossômulos de Schistosoma mansoni em ratos Holtzmian. Belo Horizonte, 1984. (Tese de doutoramento - Instituto de Ciências Biomédicas da Universidado Federal de Minas Gerais).

11. HARRISON, R. A.; BICKTE, Q. \& DOENHOFF, M. J. - Factors affecting the acquisition of resistance against Schistosoma mansoni in the mouse. Evidence that the mechanism which mediate resistance during early patent infections may lack immunological specificity. Parasitology, 84: 93-110, 1982.

12. HUNTER; G. W.; GRANDALL, R. R.; ZICKAFOOSE, D. E. \& PURVIS, Q. B. - Studies on schistosomiasis. XVIII. Some factors affecting resistance to Schistosoma mansoni infections in albino mice. Amer. J. trop. Med. Hyg., 11: 17-24, 1962.

13. JAMES, S. L. \& COH.EY, D. G. - A method for isolation of Schistosema mansoni egg. J. Parasit., 60: 1043-1044, 19.4 .

14. JAMES, S. L.; LUCAAS, S. B. \& DOBINSON, A. R. Pathology associated with vaccination against Schis. tosoma mansoni in mice using cryopreserved radiationattenuated schistosomula. J. Kelminth., 59: 51-55, 1985 .

15. LEWIS, F. A.; HWWNY, S. \& SHHRR, A. - Evidence against the existence of specific Schstosoma mansoni subpopulations which are resistant to irradiated vaccineinduced immunity. Amer. J. trop. Med. Hyg., 34: 86-91, 1985.

16. LONG, E.; DOENHOFF, M. \& BATN, J. - Factors affecting the acquisition of resistance against Schistosoma mansoni in the mouse. 2. The time at which resistance to reinfection develops. J. Helminth., 52: 87-191, 1978
17. MANGOLD, B. L. \& DEAN, D. A. - The migration and survival of gammairradiated Schistosoma mansomi larvae and the duration of host parasite contact in relation to induction of resistance in mice. $\mathbf{P a}$ rasitology, 88: 249-266, 1984.

18. MASTIN, A. J.; BICKLE, Q. D. \& WILSON, R. A. Schistosoma mansoni: migration and attrition of irradiated and challenge schistosomula in the mouse. Parasitology, 87: 87-102, 1983.

19. MhLAREN, D. J.; PEARCE, E. J. \& SMTTHERS, S. R. - Site potential for challenge attrition in mice, rats, and guinea pigs vaccinated with irradiated cercariae of Schistosoma mansoni. Paras. Immunol., 7: 29-44, 1985.

20. MONGE, E.; COFLHO, P. M. Z. \& TAVARES, C. A. P. - Estudios inmunologicos en hamsters (Cricetus auratus) infectados con Schistosoma masnoni. Rev. Inst. Med. trop. S. Paulo, 28: 239-245, 1986.

21. OLIVIER, L. \& SCFNEIDMANN, M. - Acquired resistance to Schistosoma mansoni infection in laboratory animals. Amer. J. trop. Med. Hyg., 2: 289-306, 1953.

22. PELlegrino, J. \& SIQUEtRA, A. F. - Técnica de perfusão para colheita de Schistosoma mansoni em cobaias experimentalmente infestadas. Rev. bras. Malar., 8: 589-597, 1956.

23. PEREIRA, L. H.; COELHO, P. M. Z.; FONSECA, J. J. A.; BREDT, A. \& PHLLlegrino, J. - Migration of Schistoosma mansoni larvae in the albino mouse. Rev. Inst. Med. trop. S. Paulo; 14: 306-309, 1972 .

24. PEREIRA, L. H.; PELLEGRINO, J.; MELLO, R. T.; VALADARES, T. E. \& COELFO, P. M. Z. - New approach for the screening of antischistosomal agents on early developing forms of Schistosoma mansoni. Rev. Inst. Med. trop. S. Paulo, 16: 123-126, 1974.

25. PEREZ, H. A.; CLEGG, J. Q. \& SMITHEHR, S. R. Acquired imunity to Schistosoma mansoni in the rat: measurement of immunity by the lung recovery technique. Parasitology, 69: 349-359, 1974

26. SHER, A.; CORREA.OLIVFIRA, R.; HIENY, S. \& HUSSAIN, R. - Mechanisms of protective immunity against Schistosoma mansoni infection in mice vaccinated with irradiated cercariae. IV. Analysis of the role of immunoglobulins $\mathbf{E}$ antibodies and mast ctlls. J. Immunol., 131: 1460-1465, 1983.

27. SHER, A.; HIENY, S. \& JAMES, S. - Mechanisms of protective immunity against Schistosoma mansoni infection in mice vaccinated with irradiated cercariae. VI. Influence of the major histocompatibility complex. Paras. Immunol., 6: 319-328, 1984.

28. SIMPSON, A. J. G.; AMES, S. I. \& SHER, A. Identification of surface antigens of schistosomula of Schistosoma mansoni recognized by antibodies from mice Immunized by chronic infection and by exposure to highly irradiated cercarise, Infect. Immun., 41: 591-597. 1983. 
COFH.FO, P. M. Z.; GERKEN, S. E. \& TAVARES, C. A. P. - Schistosoma mansoni: implante do vermes na cavidado peritoneal visando imunoproteção. Rev. Inst. Med. trop. São Panlo, 29:361-366, 1987.

29. SMTTH, M. A. \& CLEGG, J. A. - Schistosoms mansoni: decay of resistance induced .by gamma irradiated cercariae in the mouse. Trans. roy. Soc. trop. Med. Hyg., 8: 190-192, 1984.

30. SMITHERS, S. R. \& TERRY, R. J. - Acquired resistance to experimental infection of Schistosoma mansoni in albino rat. Parasitology, 55: 611-717, 1965.

31. SMTTHERS, S. R. \& TERRY, R. J. - Resistance to experimental infection with Schistosoma mansoni in rhesus monkey induced by transfer of adult worms. Trans. roy. Soc. trop. Med. Hyg., 61: 517-523, 1967.
32. SNEDECOR, G. W. \& COCERAN, W. G. - Statistical. methods. Iowa, Iowa State University Press, 1967.

33. WARREN, K. S. - The immunopathogenesis of schistosomiasis: a multidisciplinary approach. Trans, roy: Soc. trop. Med. Hyg., 66: 417-434, 1972.

34. WIISON, R. A.; COULSON, P. S. \& MaHUGH, S. M. - A significant parte of "concomitant immurity" of mice to Schistosoma mansoni is the consequence of a leaky hepatic portal system, not immune klling. Paras. Immunol. 5: 595-601, 1983.

Recebido para publicaçа em 9/3/1987. 